\title{
Destruction, Amorphization and Reactivity of Nano-BN Under Ball Milling
}

\author{
A. N. Streletskii \\ Russian Academy of Sciences \\ D. G. Permenov \\ Federal State Unitary Enterprise
}

B. B. Bokhonov

Russian Academy of Sciences

Follow this and additional works at: https://engagedscholarship.csuohio.edu/sciphysics_facpub 'i'. Kolbanev

Msspath Afcthemy ófísciencesons

How does access to this work benefit you? Let us know! \section{Pulbtish
Moscow's State Shlversityent}

NOTICE: this is the author's version of a work that was accepted for publication in Journal of Alloys and Compounds. Changes resulting from the publishing process, such as peer review,

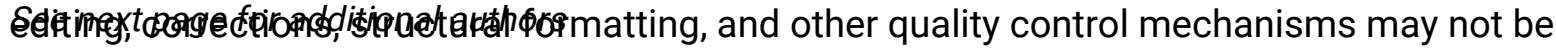
reflected in this document. Changes may have been made to this work since it was submitted for publication. A definitive version was subsequently published in Journal of Alloys and Compounds, 483, 1-2, August 26, 2009 DOI\#10.1016/j.jallcom.2008.08.088

\section{Repository Citation}

Streletskii, A. N.; Permenov, D. G.; Bokhonov, B. B.; Kolbanev, I. V.; Leonov, A. V.; Berestetskaya, I. V.; and Streletzky, Kiril A., "Destruction, Amorphization and Reactivity of Nano-BN Under Ball Milling" (2009).

Physics Faculty Publications. 253.

https://engagedscholarship.csuohio.edu/sciphysics_facpub/253

This Article is brought to you for free and open access by the Physics Department at EngagedScholarship@CSU. It has been accepted for inclusion in Physics Faculty Publications by an authorized administrator of EngagedScholarship@CSU. For more information, please contact library.es@csuohio.edu. 


\section{Authors}

A. N. Streletskii, D. G. Permenov, B. B. Bokhonov, I. V. Kolbanev, A. V. Leonov, I. V. Berestetskaya, and Kiril A. Streletzky 


\title{
Destruction, amorphization and reactivity of nano-BN under ball milling
}

\author{
A.N. Streletskii ，D.G. Permenov , B.B. Bokhonov , I.V. Kolbanev , A.V. Leonov , \\ I.V. Berestetskaya , K.A. Streletzky
}

\section{Introduction}

Hexagonal boron nitride (h-BN) is analogous to graphite in its crystallographic parameters. The structure of $\mathrm{h}-\mathrm{BN}$ is presented by layers of flat $\mathrm{B}_{3} \mathrm{~N}_{3}$ hexagons packed in the [001] direction with alternating nitrogen and boron atoms one over another. There is a metastable turbostratic BN (t-BN) [1] in which hexagon layers are located in parallel to each other, but azimuthal disposition of hexanes is chaotic. The disorder in the disposition of hexagon layers results in enlarged interlayer distance $d_{002}$.

The mechanical activation of $\mathrm{h}-\mathrm{BN}$ is promising for production of superhard cubic BN [2], nanotubes [3], creation of layered composites [4], etc. The first data about processes taking place under ball milling of h-BN are given in [2-6]. This paper studies the mechanisms of h-BN mechanical activation and the onset of chemical activity as a result of mechanical treatment.

\section{Experimental techniques}

Mechanochemical activation was carried out in a vibration ball mill with vials and balls made of hardened bearing steel under protective $\mathrm{Ar}$ atmosphere. The ball-to-powder weight ratio was 60:1. The depth of mechanical activation was characterized by the dose $D$ of energy supplied to the material under milling instead of widely used milling time [7]. The dose $(\mathrm{J} / \mathrm{g})$ is defined as $D=J t$, where $J$ is specific power intensity of the mill and $t$ is milling time. The value of $J$ was $36 \mathrm{~W} / \mathrm{g}$.

Mechanochemical hydrogenation was carried out in a laboratory vibration mill, hermetically joined to a vacuum device. The $\mathrm{H}_{2}$ absorption was measured by the pressure fall in known volume [8]. The $\mathrm{H}_{2}$ pressure was (3-5) $\times 10^{4} \mathrm{~Pa}$. Power intensity of the mill was $1 \mathrm{~W} / \mathrm{g}$.

Structural characterization of milled samples was performed by X-ray diffraction (XRD) with monochromatized $\mathrm{Cu} \mathrm{K} \alpha$ radiation (DRON-3 device). Values of coherent scattering region (CSR), $L$, and microstresses, $\varepsilon$, were calculated on the basis of the line profile analysis of X-ray spectra using Ref [9]. For very broad lines the $L$ value was estimated using Sherrer's formula. Specific surface area of the powders was determined using the low-temperature ( $77 \mathrm{~K}$ ) BET Ar adsorption technique. Measurements by transmission electron microscopy (TEM) were carried out on an electron microscope Jeol JEM 2000 FX II. Fourier Transformation Infra Red (FTIR) spectroscopy measurement used AF-1 instrument. For the Dynamics Light Scattering (DLS) experiments $\mathrm{Ar}^{+}$laser ( $1 \mathrm{~W}$ of power at $514.5 \mathrm{~nm}$ ) with multiangle photometer-goniometer (BI 200SM) and BI-9000 correlator were used. DLS experiments were performed in methanol suspensions of $\mathrm{BN}$ powders. CONTIN algorithm [10] was employed for analysis of the DLS data. Characteristics of original h-BN (purity 99\%) are described in detail in Section 3.1.

\section{Results and discussion}

\section{Characteristics of original $h-B N$}

As was shown by TEM, the original h-BN samples were tablets (Fig. 1) with diameter of $300-500 \mathrm{~nm}$ and thickness of $70-80 \mathrm{~nm}$. 


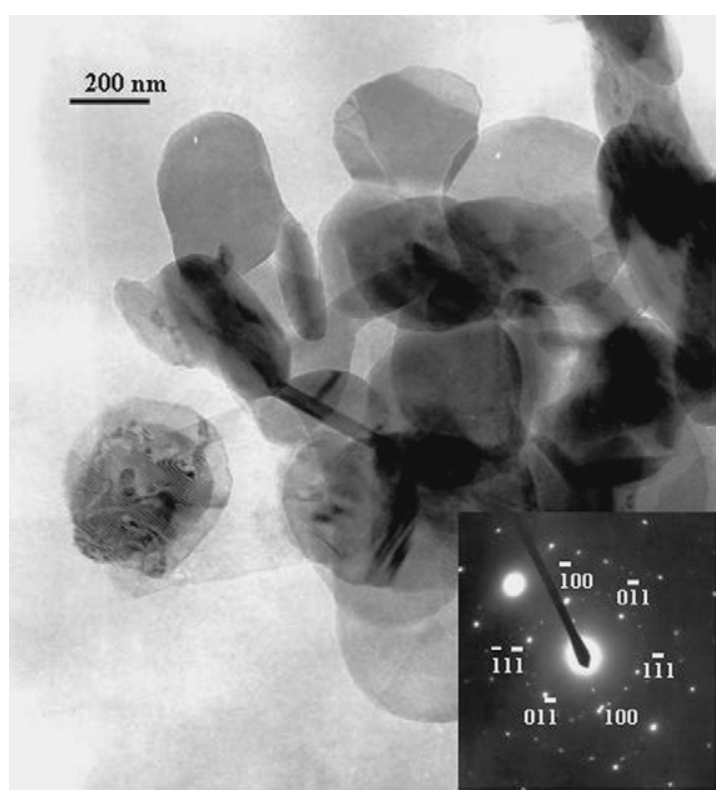

Fig. 1. TEM image and selected area electron diffraction for initial h-BN.

The reflection on selected area electron diffraction pattern corresponds to h-BN (Fig. 1) and suggests that the tablets are monocrystalline. The original h-BN XRD pattern indicates that the intensity of lines 002 and 004 is essentially higher than in the standard spectrum (texturing). In addition, lines 002 and 004 are noticeably widened. The line widening is due only to reduction in size of $L$ of CSR: $L(002 / 004)=84 \pm 15 \mathrm{~nm}, \varepsilon(002 / 004)=0$. The lines in the direction of [ 100$]$ are not widened, allowing to conclude

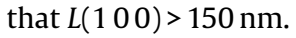

The value of specific surface area $(S)$ measured by BET of original h-BN sample is $S=12 \mathrm{~m}^{2} / \mathrm{g}$. For flat tablets of thickness $\mathrm{h}$, which is considerably smaller than the tablet diameter, the geometrical specific surface area is $S \approx 2 / \rho h$ (here $\rho$ is density). The thickness estimate based on this formula gives the value of $h=71 \mathrm{~nm}$. Thus, the results on the tablet thickness are confirmed by three independent methods.

Therefore, we can conclude that the original h-BN samples are microcrystalline and have the shape of tablets with diameter of $300-500 \mathrm{~nm}$ and thickness of $70-80 \mathrm{~nm}$. The flat side of tablets corresponds to the basal plane [001].

\section{The BN destruction and amorphization under ball milling}

Fig. 2 shows the dependence of specific surface area measured by BET on the dose of mechanical treatment. At the initial stage of mechanical treatment specific surface area increases with increase of the dose, reaches maximum of about $400 \mathrm{~m}^{2} / \mathrm{g}$ (at the dose of $6-8 \mathrm{~kJ} / \mathrm{g}$ ), and then decreases as the dose continues to increase. Adsorption measurements in the broad interval of pressure have shown no microporosity at the initial stage of mechanical treatment.

Fig. 3a shows a microphotograph and microdiffraction pattern for the BN sample activated under the dose of $2.2 \mathrm{~kJ} / \mathrm{g}$. Apparently, the activated sample consists of long "rods" with 5-25 nm thickness. Selected area electron diffraction (SAD) patterns of the phase, formed during the ball milling (Fig. 3a), is characterized by the presence of the diffraction rings of polycrystalline boron nitride. The calculated interstitial distances for ring-type reflections are: 3.33, 2.16, 2.07 and $1.82 \AA$, which is in good agreement with the hexagonal boron nitride parameters. For the sample under the dose of

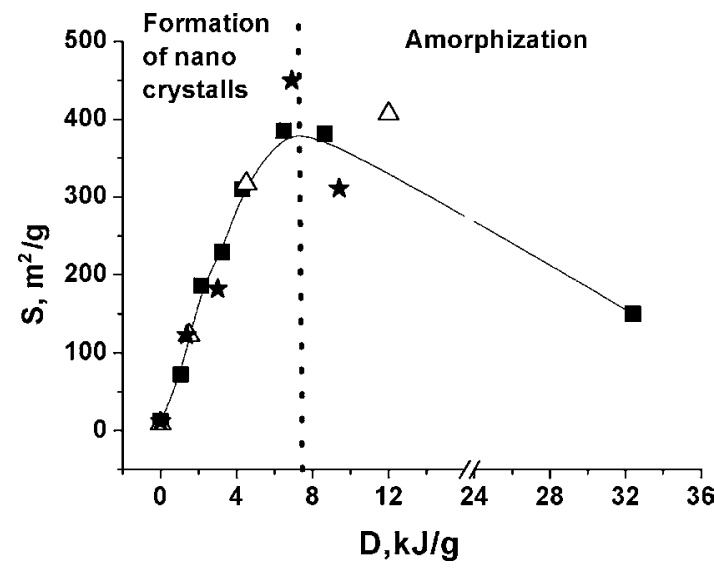

Fig. 2. Specific surface area of $B N$ under ball milling.

$4.3 \mathrm{~kJ} / \mathrm{g}$, the rods are significantly smaller (most rods are thinner than $5 \mathrm{~nm}$ ). For this dose the SAD patterns show reflexes of polycrystalline boron nitride and an amorphous halo (primary data are not shown). Finally, for the sample under the dose of about $22 \mathrm{~kJ} / \mathrm{g}$ (Fig. 3b) SAD corresponds to almost completely amorphous material.

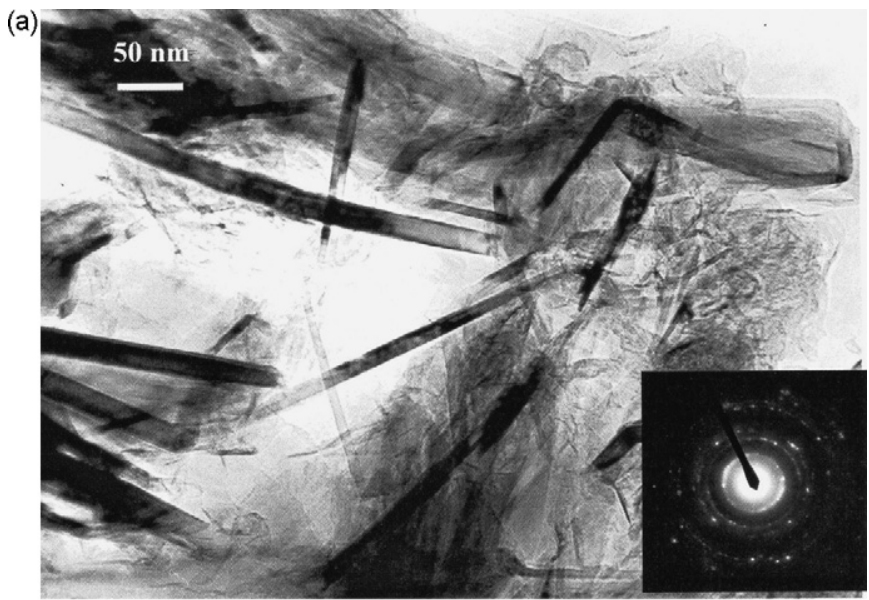

(b)

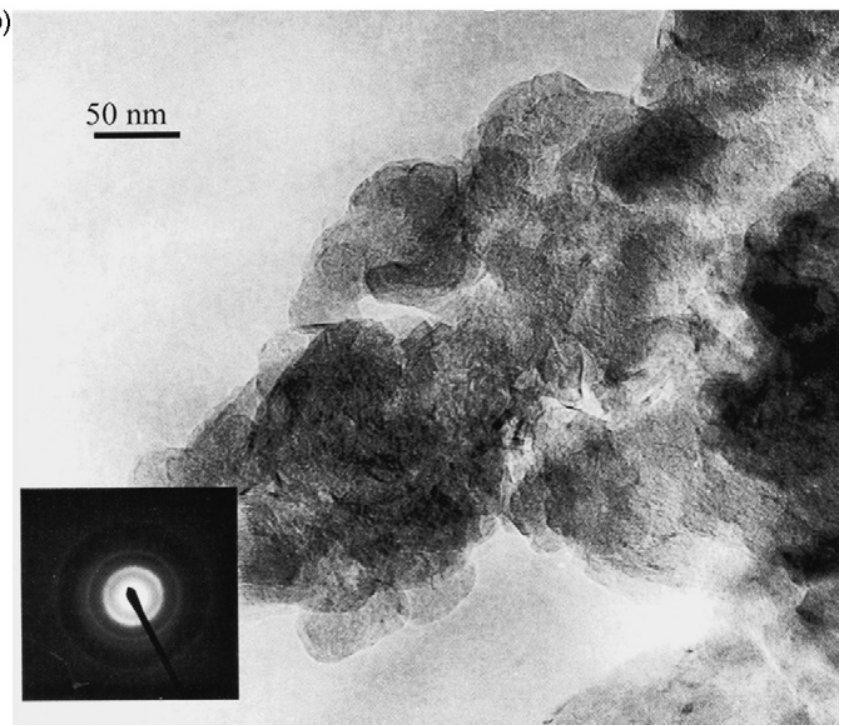

Fig. 3. TEM image and selected area electron diffraction for mechanically activated BN under the dose of 2.2 (a) and 22 (b) $\mathrm{kJ} / \mathrm{g}$. 
Table 1

Comparison of the rod thickness obtained by TEM, BET and DLS techniques.

\begin{tabular}{lllll}
\hline$N$ & Dose $(\mathrm{kJ} / \mathrm{g})$ & TEM & BET & DLS \\
\hline 1 & 2.2 & $5-25 \mathrm{~nm}$ & $10 \mathrm{~nm}$ & - \\
2 & 4.3 & $<5 \mathrm{~nm}$ & $6 \mathrm{~nm}$ & $5.5 \mathrm{~nm}$ \\
\hline
\end{tabular}

It is natural to assume that, in the absence of micropores, specific surface area is the external surface of the rods. Under the assumption that rods length considerably exceeds their thickness the specific surface area $S$ is found to be about $4 / \rho \mathrm{h}$. Table $1 \mathrm{com}-$ pares h values, calculated using this formula with the data of TEM. Clearly a satisfactory agreement is observed.

XRD patterns of mechanically activated $\mathrm{BN}$ under various doses are presented in Fig. 4. As doses of mechanical treatment increase, the BN lines widen. The lines 002 and 004 are widened much more than the line 100 . For the dose of $2.2 \mathrm{~kJ} / \mathrm{g}$ the CSR size estimated using Sherrer's formula for the line 002 was $L(002) \sim 30 \mathrm{~nm}$ and for the line 100 it was $L(100)>130 \mathrm{~nm}$. The anisotropy of roentgen line widening could indicate that rods are crystallographically oriented and their long side has a direction [ 1000$]$.

Under higher doses of mechanical activation, at the stage of reduction of specific surface two broad maxima are observed on diffractograms. The CSR formal estimation for diffractogram 7 in Fig. 4 results in $L(002) \sim 1.2-1.5 \mathrm{~nm}$.

Additional confirmation that the entire activated material at low doses consists of long rods is obtained from the Dynamic Light Scattering (DLS) spectroscopy. This method yields the translational and the rotational diffusion coefficients $\left(D_{\mathrm{tr}}, \Xi\right.$, respectively) of particles in solution (and/or suspension) from which the distribution of the apparent hydrodynamic radius and the shape of particles can be deduced. The shape of the size distribution function at different scattering angles for activated sample with the dose of $4.3 \mathrm{~kJ} / \mathrm{g}$ reveals that: (1) BN particles have strongly anisotropic shape, (2) $D_{\text {tr }}=3.97 \times 10^{-12} \mathrm{~m}^{2} / \mathrm{s}$ and $\Xi=289.4 \mathrm{~s}^{-1}$, (3) the rigid rod scattering model [11] suggests that the rods of the $450 \mathrm{~nm}$ in length and $5.5 \mathrm{~nm}$ in diameter is one possible solution that produces the values of $\Xi$ and $D_{\mathrm{tr}}$ that are similar to experimental values. The value of $5.5 \mathrm{~nm}$ for sample 2 in Table 1 is similar to the values obtained from other methods.

In summary, mechanical treatment in the ball mill can be divided into two stages: under doses up to $6-8 \mathrm{~kJ} / \mathrm{g}$ monocrystalline tablets of h-BN are cleaved to nanocrystalline rods, specific surface of which reaches hundreds of $\mathrm{m}^{2} / \mathrm{g}$; under higher doses the amorphization processes start to appear and reduction of specific

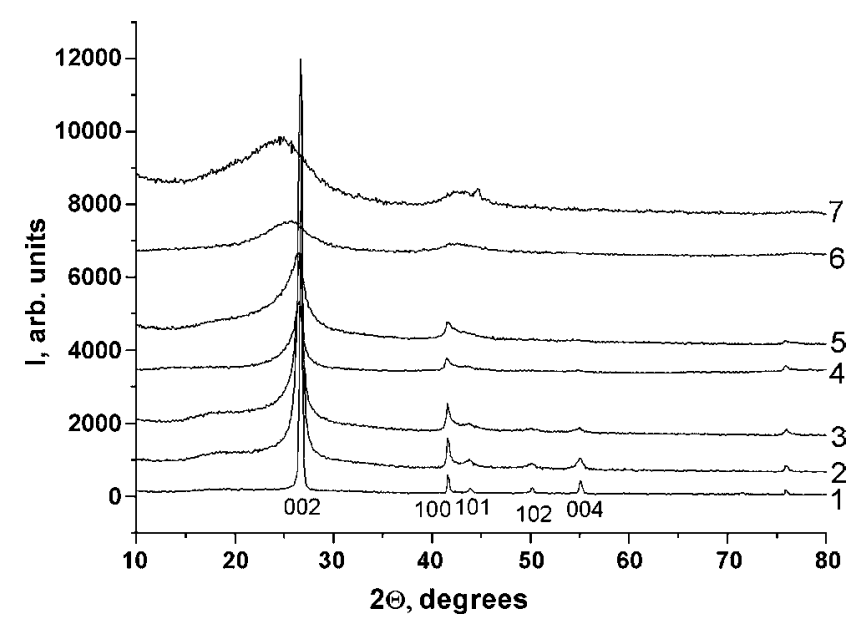

Fig. 4. X-ray diffraction patterns of BN after mechanical activation. Diffractograms correspond to doses: 0(1), 2.2 (2), 4.3(3), 6(4), $8.6(5), 25$ (6) and 32(7) kJ/g.

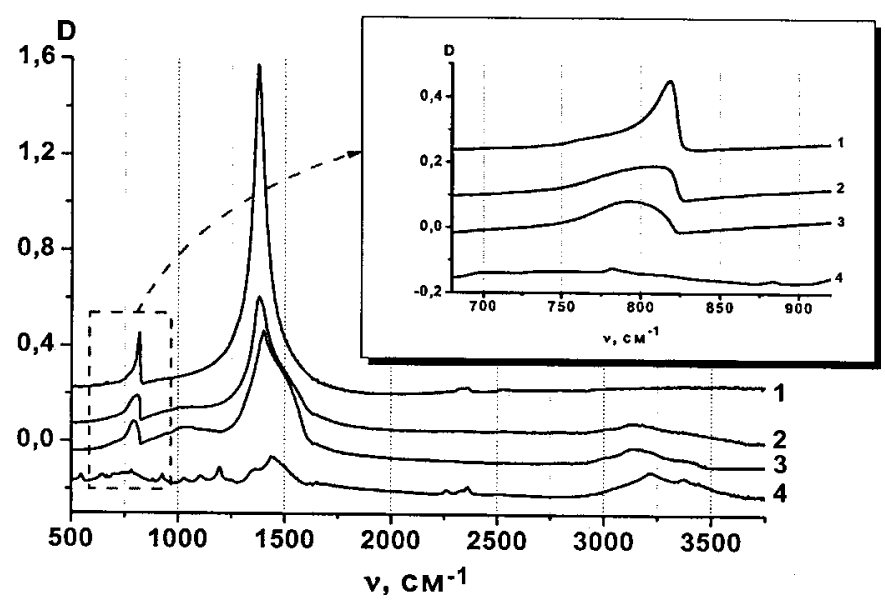

Fig. 5. FTIR spectra of initial h-BN sample (1) and ball milled samples with doses of 6.5 (2) and $22(3) \mathrm{kJ} / \mathrm{g}$ as compared with the model FTIR pattern for $\mathrm{B}_{2} \mathrm{O}_{3}$ (4).

surface begins. By the moment when amorphization processes are dominant transversal dimension of "nanorods" is less than several nanometers.

It was found that the mechanical treatment causes a shift of XRD lines 002 and 004 towards small angles in addition to their widening. Also, the lines become anisotropic in shape (Fig. 4) under the treatment. The shift of lines 002 and 004 towards small angles points to the increase in the $d_{002}$ distance between basal planes in BN. By the dose of $10 \mathrm{~kJ} / \mathrm{g}$, the distance estimated by position of line 002 maximum, $d_{002}$, increases from 0.3343 to $0.3365 \mathrm{~nm}$. The anisotropy of the line 002 indicates possible formation of several fractions, differing by the extent of lattice "swelling". It appeared that the shape of line 002 can be described satisfactory with the assumption of three or four fractions present. The more pronounced the lattice "swelling" is in a fraction, the wider the line in this fraction is.

"Swelling" of the mechanically activated BN lattice has also been confirmed by FTIR spectroscopy. The FTIR spectra of original h-BN sample have two bands at $\sim 820$ and $\sim 1370 \mathrm{~cm}^{-1}$ (Fig. 5). According to [12], the band with the maximum at $1370 \mathrm{~cm}^{-1}$ corresponds to in plane vibration and the band at $817 \mathrm{~cm}^{-1}$ corresponds to out-ofplane vibrations. Fig. 5 shows that the mechanical activation results in a shift of the band from $820 \mathrm{~cm}^{-1}$ towards low frequencies by about $20 \mathrm{~cm}^{-1}$. The shift of this band is indicative of the increase in the interlayer distance $d_{002}[13]$.

Mechanical activation also results in appearance of new bands in FTIR spectra at 1030,1500, and $3150 \mathrm{~cm}^{-1}$. Control experiments

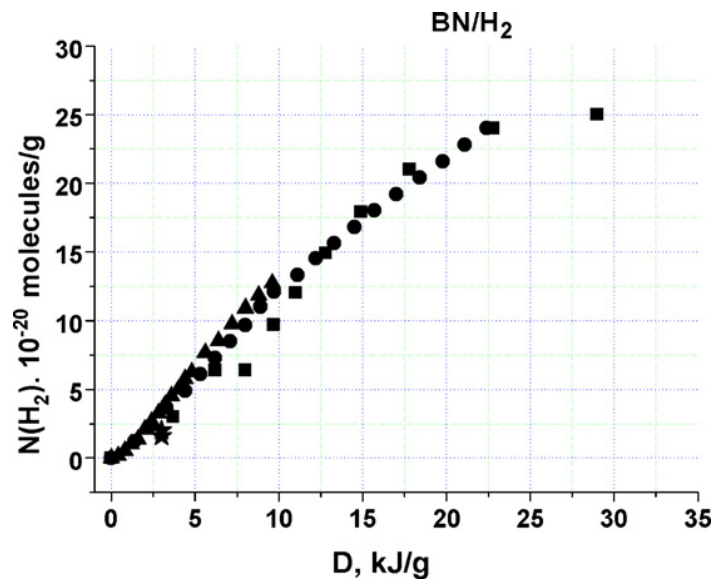

Fig. 6. Consumption of $\mathrm{H}_{2}$ during ball milling of $\mathrm{BN} . \mathrm{H}_{2}$ pressure is (3-5) $10^{4} \mathrm{~Pa}$. 
Table 2

The depth $(\alpha, \%)$ of $\mathrm{BN}+\mathrm{H}_{2} \mathrm{O}$ reaction at different temperatures.

\begin{tabular}{lcc}
\hline Dose $(\mathrm{kJ} / \mathrm{g})$ & $\alpha_{1}\left(T=20^{\circ} \mathrm{C}\right)$ & $\alpha_{2}\left(T=70-90^{\circ} \mathrm{C}\right)$ \\
\hline 2.2 & 3 & - \\
6.5 & 5 & 13 \\
22 & 3 & 36 \\
32 & 17 & 56 \\
\hline
\end{tabular}

have shown that the appearance of new bands at 1500 and $\sim 3200 \mathrm{~cm}^{-1}$ may be attributed to $\mathrm{B}_{2} \mathrm{O}_{3}$. Boron oxide emerges in the samples, probably, as a result of the activated $\mathrm{BN}$ hydrolysis by water vapors from atmosphere during storage (see Section 3.4).

\section{Mechanochemical hydrogenation of $B N$}

Fig. 6 shows the dependence of the amount of absorbed hydrogen molecules on the dose of mechanical treatment. The rate of hydrogen absorption is nearly constant up to the doses of about $8 \mathrm{~kJ} / \mathrm{g}$ and then it slightly decreases with the increase of the dose. Maximum amount of absorbed hydrogen under experimental conditions is $0.8 \mathrm{wt} \%$.

Under the dose of $8 \mathrm{~kJ} / \mathrm{g}$ the specific surface area appears to be equal to $S=250 \mathrm{~m}^{2} / \mathrm{g}$ and the amount of absorbed hydrogen molecules is $N=1.3 \times 10^{21}$ molecules/g. This corresponds to the surface filling $\mathrm{N} / \mathrm{S}$ with about $1 \times 10^{15}$ hydrogen atoms per $\mathrm{cm}^{2}$, i.e. the filling is close to monolayer type of filling. After hydrogen chemosorption, the BN (band $2600 \mathrm{~cm}^{-1}$ ) and $\mathrm{NH}$ (band $3086 \mathrm{~cm}^{-1}$ ) groups formation was observed by FTIR method. It can be assumed that hydrogen interacts with disrupted bonds of -B...N-, that inevitably appear upon cleavage of boron nitride particles with formation of "nanorods" according to the reaction

$-\mathrm{B}-\mathrm{N}-\rightarrow-\mathrm{B} \cdots \mathrm{N}-+\mathrm{H}_{2} \rightarrow-\mathrm{BH}+\mathrm{HN}-$

Upon heating of hydrogenated samples to $800^{\circ} \mathrm{C}$ the gases of $\mathrm{H}_{2}$ and $\mathrm{NH}_{3}$ are released.

\section{Hydrolysis of mechanically activated $h-B N$}

Original boron nitride is chemically inert, including its zero sensitivity to oxidation up to $1000^{\circ} \mathrm{C}$. After mechanical activation $\mathrm{BN}$ acquires the ability to interact with water at room temperature according to the reaction

$2 \mathrm{BN}+3 \mathrm{H}_{2} \mathrm{O} \rightarrow \mathrm{B}_{2} \mathrm{O}_{3}+2 \mathrm{NH}_{3} \uparrow$,

Ammonia formation was registered organoleptically and by chemical analysis. The appearance of $\mathrm{B}_{2} \mathrm{O}_{3}$ was confirmed by observation of absorption bands in FTIR spectrum at $1500 \mathrm{~cm}^{-1}$ and in the region of $3000-3500 \mathrm{~cm}^{-1}$. The depth of the reaction 2 (determined by gravimetric technique) increases as the dose of mechanical treatment increases. It reaches $56 \%$ at the dose of $32 \mathrm{~kJ} / \mathrm{g}$ (Table 2). The difference between results obtained with cold and hot water in
Table 2 is probably due to formation of the glass-like modification of boron oxide, which is practically insoluble in cold water and is soluble upon heating above $60^{\circ} \mathrm{C}$.

The most disordered part of activated boron nitride is involved in the reaction 2 with water. The XRD line of BN observed before the hydrolysis does not disappear after interaction with water, but becomes narrower.

\section{Conclusions}

Two processes take place during mechanical treatment of h-BN monocrystals. At the initial stage of mechanical treatment, the main process is cleavage of boron nitride plates in the plane (001) and formation of crystallographically oriented nanodimensional rods. The external specific surface of the rods reaches $400 \mathrm{~m}^{2} / \mathrm{g}$.

The particle cleavage stimulates boron nitride hydrogenation (reaction 1) with formation of - $\mathrm{BH}$ and $\mathrm{HN}$ - groups in a concentration similar to monolayer. The detailed mechanism of amazing processes of "oriented" cleavage requires further investigation.

The second process happening during the mechanical treatment is disordering of the BN crystalline structure. This is revealed in the increase of interlayer distance $d_{002}$, registered by XRD and FTIR techniques. It is possible that the lattice "swelling" is due to the processes of shifting along the plane (001), resulting in the loss of mutual orientation of these planes and boron nitride transition to the turbostratic and amorphous structures. Amorphization of BN is accompanied by the emergence of chemical activity during interaction with water (reaction 2 ). As a result of mechanical activation the depth of reaction 2 is near $60 \%$ even at $100{ }^{\circ} \mathrm{C}$, whereas for hydrating of non-activated $\mathrm{BN}$ the temperature has to be raised to $1000^{\circ} \mathrm{C}$.

\section{Acknowledgements}

The work was carried out under financial support of Presidium RAS Program (no. 08-P), RFBR (grant 07-03-00610) and INTAS (grant 05-1000005-7672).

\section{References}

[1] J. Tomas Jr., N.E. Weston, T.E. O'Connor, J. Am. Chem. Soc 84 (1963) 4619.

[2] Z.P. Xia, Z.Q. Li, J. Alloys Compd. 436 (2006) 170.

[3] Y.Chen, L.T. Chadderton, J.F. Gerald, J.S. Williams, Appl. Phys. Let. 74(1999) 2960

[4] A.N. Streletskii, D.G. Permenov, I.V. Povstugar, S.N. Mudretsona, I.V. Berestetskaya, Chem. Sustainable Dev. 15 (2007) 175 (in Russian).

[5] J.Y. Huang, H. Yasuda, H. Mori, J. Am. Ceram. Soc. 83 (2000) 403.

[6] X.J. Du, F.Q. Guo, K. Lu, Nanostruct. Mater. 5 (1996) 579.

[7] P.Yu. Butygin, I.K. Pavlichev, Reactivity Solids 1 (1986) 361.

[8] P.Yu. Butyagin, A.N. Streletskii, I.V. Berestetskaya, et al., Colloid J. 63 (2001) 639

[9] E.V. Shelekhov, Proceeding of National Conference on X-ray, SR, Neutrons and Electrons Application for Mat. Sci. Investigation, Dubna, V.3, 1997, p. 316 (in Russian).

[10] K.M. Zero, R. Recora, Macromolecules 15 (1982) 87

[11] B.J. Berne, R. Pecora, Dynamic Light Scattering, Wiley, New York, 1976

[12] R.J. Nemanich, S.A. Solin, R.M. Martin, Phys. Rev. B23 (1981) 6348.

[13] A.S. Rozenberg, Yu.A. Sinenko, N.V. Chukanov, J. Mater. Sci. 28 (1993) 567. 